\title{
Analyzing and Managing Financial Sustainability of the Company in Turbulent Environment
}

\author{
Elena Borisovna Gerasimova \\ Financial University under the Government of the Russian Federation, \\ 49 Leningradsky Prospekt, Moscow, Russia, 125993, GSP-3 \\ Email egerasimova@fa.ru \\ Dmitrii Vladimirovich Redin \\ Moscow state university of mechanical engineering (MAMI), 107023, \\ Moscow, Bolshaya Semenovskaya str., 38 \\ Emaildmired@mail.ru
}

Doi:10.5901/mjss.2015.v6n4p138

\section{Abstract}

Until now, the debates around financial sustainability analysis, estimation and management have converged towards two main issues. The first is about financial analysis practice based on different sources of information, comparative value of financial and managerial accounting. The second is about institutional restrictions that factually replace the theory of analysis and management. In this paper, we explore an underdeveloped topic by linking these two issues: how the methodology of economic analysis (with reference to financial sustainability analysis) is developed regarding claims of different groups of stakeholders. First, we extend the term "financial sustainability" putting together financial and nonfinancial indicators and metrics. We regard this as an answer on present-day challenges of turbulent environment, the turbulent nature of economic activity. Secondly, we suggest a system of indicators of financial sustainability analysis. It includes service quality and management quality indicators, financial ratios and other indicators and operating risk indicators. Finally we introduce the main goal of financial sustainability analysis - to search, discover and mobilize the reserves (working balances), disclosed and implicit opportunities of further development. We put forward an idea of socio-economic nature of these opportunities.

Keywords: financial sustainability analysis, turbulence, quality management, economic analysis, working balances, reserves, system of indicators of financial sustainability

\section{Introduction}

Financial sustainability of the modern company is the most complicated task for analysis. Classic interpretation of financial sustainability including analysis of fund structure, asset-liability management, gap-analysis does not work anymore, at least it's not so efficient as it was as far back as 2000 s.

Today commercial firms and government institutions manage activities in a situation of permanent instability. Moreover this instability regarded as a new form of business conditions, as something inevitable, a new character of modern business. Thus analytical work ought to be rearranged on the basis of both - objective and subjective - methods of attack.

Drawing a parallel between economics and exact sciences we could describe the situation as a combination of a physicist and mathematician thinking style. Well known is the great difference between a physicist and a mathematician while they make their research. Without going into details mathematicians tend to discover objective laws of the universe frequently in abstracto, while physicists base their conclusions on an experimental basis, which are organized and interpreted with a fair share of subjectivity and individual style.

Modern economic systems could not be described as "hand-made", artificial systems; economic systems give the impression to have some features of bio-systems, namely self-organization and self-improvement, the last is carried out by overpowering performance crisis. The core point is the certain element of economic system that makes it possible for the economic system to act as bio-system. We consider a manager (in a broad sense) to be this element.

Self-organized economic systems contribute new management approach, based on the internal and external business environment analysis. The heart of the problem is that business processes could not be managed as linear 
cause they are turbulent. Turbulence (physical process) occurs not only in nature, hydro and aero-dynamic objects, but in economic systems as well.

The turbulence of business processes easy to see while studying them thoroughly. Managing turbulent processes in a turbulent environment mostly look like prediction. Managers need answers on numerous questions, particularly: What certain processes influence activities of individuals and corporations in circumstances of permanent economic transformations? What factors influence economic performance and how they are analysed taking into account that traditional economic methods couldn't forecast changes? What put an end to apparently stable business? What prohibit managers from gaining competitive advantages and favourable market conditions?

Traditional management conflicts with turbulent processes. Management system is mainly characterized by the order and is responsible for the effectiveness of business processes. But business processes themselves are not ordered, they are turbulent, chaordered. Thus to overpower and use the turbulent phenomena management system must constantly work on its quality. Under this condition turbulent business processes could gain advantages for the company that laminar processes couldn't provide. In that way economic system get synergetic effect. Moreover - high-quality management could predict or measure this effect through analysis and management of turbulent processes.

This topic also raises the problem of social responsibility. Society is concerned about the quality of corporate management and related services. Especially they are interested in financial services, audit, consulting, insurances, on the whole in all spheres that could influence the life quality. That means that society recognizes the turbulent character of economic processes, but has difficulties in assessing the situation.

The baffling complexity of the analytical work in the field of economics and finance consists in the barest necessity of a comprehensive interdisciplinary approach to the analysis of a company activity.

\section{Review on Literature}

Discussion on financial sustainability concept is beyond the field of economics. From the very beginning the term was closely connected with technical term "reliability". According to Merriam-Webster Dictionary reliability is the quality or state of being reliable; the extent to which an experiment, test, or measuring procedure yields the same results on repeated trials (Merriam-Webster, 2014).If they identify financial sustainability with reliability mismatching appears. Because in terms of finance making something constant means making it dead (if not the very moment, tomorrow in certain).

The meaning and internal structure of the category of financial sustainability was discussed for years after Russia has been adopted market reforms. In general economists determine financial sustainability as complex of characteristics that describe the field of finance of the firm. From this practical point of view there is no need to define an economic category "financial sustainability", making list of specific components is quite sufficient. Economists discuss sustainability of financial system of the world or a country. Larionova (2003) determines sustainability of the bank system as it capability to execute functions and to meet law requirements. Thus the sustainability of separate bank is outlined briefly by a minimum of requirements. Evidently it's not sufficient, because the efficiency if management is determined not by a minimum of requirements, but by benchmarks, highest possible standards, best practice.

Analyzing financial sustainability of a company economists write about the balance between different components. Grachev (2010) distinguishes the necessity of balancing revenues and expenses, assets and liabilities. Kreinina (2004) makes her rating system using the same list of characteristics, described by financial ratios. Endovickaya (2006) determines financial sustainability as the capability of the company to operate under the conditions of risk in interests of owners of business taking into account interests of other users of information about financial condition.

Many economists analyze financial sustainability from this point of view focusing attention on bookkeeping with its balancing assets and liabilities, revenues and expenses: Barilenko (2006), Suhova (2006), Chernenko (2010),Kovalev (2015), Doncova (2015) and Nikiforova (2015). In our opinion this approach not allows to analyze financial sustainability as a complex of different factors - financial and nonfinancial.

Discussing the financial sustainability of banks and financial institutions economists try to identify requirements of Central Bank and demands of stakeholders of a commercial bank: Mamonova (1996), Batrakova (2007), Petrova (2007), Kopchenko (2009), Veshkin (2010), Zharkovskaya (2015).

The discussion on the financial sustainability subject had developed recently to a comprehensive interdisciplinary approach to the analysis of a company activity. In our opinion the methodology of financial sustainability analysis is constructed on the basis of the economic analysis theory, quality management concept, business-analysis approach, interrelated and interconnected overall by contemporary philosophy (Gerasimova, 2010). 


\section{Principles of Financial Sustainability Analysis}

Development of financial sustainability analysis as a science is closely connected with the shifts in the economy of the organization. The more dramatic these shifts, the more diversified requirements for the work of analysts. It's not just about new tools and techniques, but also about changes in fundamental principles of analytic work.

Soviet economists had developed the theory and methodology of so called Analysis of Economic Activity (AEA), the most prominent are Sholomovich (1938), Bakanov, M.I. (1952), Pereslegin (1967), Ostrinskaya (1971), Maidanchik (1973). Soviet analysts had developed the system of principles of AEA. But these principles must be upgraded and expanded regarding actual trends in economics and finance.

Complexity is the basic standard of financial sustainability analysis. It means a comprehensive analysis of economic activity with all it cause-effect relations among different elements of the economic system. This approach principle was established by soviet economist Veicman in his book "Accounts analysis" in 1924 and developed in his classic book on balance-sheet analysis in 1940s (Veicman, 1947).

In accordance with the principle of consistency company is considered as a complex dynamic system, consisted of a number of elements related to each other and with the external environment. The organization is studied as a part of a higher level system - industry, economy of the country, global economy.

We introduce a new principle of financial sustainability analysis - complementarity. With regard to the financial sustainability analysis complementarity allows analyst to formulate recommendations for improvement of the activity of a company taking into account that the impact on one concrete indicator causes a change in some other indicators. Complementarity could be applied not only to business activity but to the activity of an analyst. The work of an analyst is complementary to the operations of the company, that means - business performance and analytics complement and enhance the results of each other.

The process approach becomes an important principle of analysis. Managing activity as a process allows to achieve the desired result more effectively. Analysis as a process because in the basis it passes through different stages, each of which has its own properties. According to our opinion analysis could be defined as the continuous process of assessing information about the company's activities. Solving specific managerial problems is also carried out in accordance with the process approach, it can be divided into several steps (stages of analysis): clarification of goals and objectives of the analysis, identification information database, choosing of the method of solving the problem, establishing the relationship between factors, the development of economic-mathematical models, carrying out decisions, development of scenarios, preparation of analytical reports (notes), presentation of analysis results to the customer.

According to actual managerial strategy continuous improvement of the company's activities should be considered as the permanent business goal. Continuous improvement as a principle of financial sustainability analysis arises because the field of analytics is changeable, floating and unbalanced. On the one hand, continuous improvement is the way for an analyst to study the activities of the company. An analyst is looking for the signs of continuous improvement in order to evaluate the results, and to develop new targets and benchmarks. On the other hand, continuous improvement means that despite the existing knowledge and experience, an analyst himself is constantly improving as an expert, developing professional skills and results, communication with professionals and other stakeholders.

This leads us to another principle of financial sustainability analysis - customer orientation. The analyst must understand current and future needs of those who use of the results of analytic work. Moreover - analysts ought to understand their requirements and strive to exceed their expectations. This is especially true for external consultants, who usually detect and deconstruct those problems, the existence of which is not evident for clients.

A systematic and complex approach to management, effective communication between managers contribute to the effectiveness of financial sustainability analysis. Ex facte this is too obvious but in practice analysis is undervalued. Theoretically the case is as follows. The analysis should actively influence the production process and its results, in a timely manner to identify gaps and bottlenecks and sources of improvement. The main task of an analyst is to inform the management of the company and other stakeholders. If the analysis results do not affect decision-making or there is no any feedback from the client (internal or external), the analysis ceases to be an effective management tool and gradually becomes a formal procedure, that in fact has no demand.

The effectiveness of financial sustainability analysis can be additionally achieved by involving employees in analytic process. In accordance with the theory of management we call this principle "employee involvement". Workers must be involved in process of collecting and preparing of material for analysis and its procedures. This could be achieved by involving employees in process improvement activities. Participation in analysis process gives employees an advantage to develop their abilities and skills. Soviet economists used similar principle - the principle of mass, which assumed involvement of engineers and economists of an enterprise into analysis process (Osmolovsky 1989). Today, 
when accounting systems require the involvement of employees of different departments (production, supply, sales and support) in the process of database preparation, the degree of involvement in analysis process also increases. Process of external analysis does not exclude employee involvement. The success of external (remote) analysis to a large extent depends on the degree of executives involvement.

Another principle of financial sustainability analysis is the planning principle. It is connected with a number of characteristics:

- analysis should be carried out continuously;

- analysis ought to comply with the plan of activity, including time constraints, executives and forms of control over the reliability of the obtained results;

- analysis should be clearly periodic;

- analysis is to be based on the assignment of responsibilities for carrying out specific analytical procedures.

We also present the principle of efficiency that is divided into two parts. On the one hand it means the ability to perform tasks and implement decisions in practice quickly and accurately. The cause of the deviation of factual values from target values must be promptly identified and warned. If failure in production and management has occurred, the efficiency will reduce the negative effects to a minimum. Factors that negatively influence changes in quantitative and qualitative indicators are analyzed online. Simultaneously the effect of positive factors (strategy appropriated) increases. On the other hand efficiency is the comparative estimate of analysis cost and effect on performance indicators. Advanced analysis of deviations from plans and strategy is carried out on significant figures only. The degree of their significance materiality - is determined by the control system. They can select quantitative criteria (for example, we analyze all deviations more than $5 \%$ of the target value) or qualitative (we analyze every case of defects in production, each case of employees absence, all customer complaints and claims for replacement).

In the basis of system of principles of financial sustainability analysis are the principles of national interest and scientific nature.

The principle of national interest means that the activity of a company must comply with law requirements, economic, environmental and social policy of the country of residence. It is especially important during planning process strategic as well as current. On a control phase it is sufficient to evaluate the degree of plan execution and variation from target values.

The scientific nature of financial sustainability analysis leads us to correlation between the methodology of analytic work and the dialectics and economic laws that reflect objective reality. Scientific nature organize principles of analysis in a system that under condition of complex application provides efficiency of financial sustainability analysis. The perception of financial sustainability analysis as a science lays the foundation of it further development, in particular, they can expand the system of principles of financial sustainability analysis by including the most important principles of organization and production management, as well as contemporary methods of scientific research.

\section{System of Financial Sustainability Indicators}

In order to imagine a system of financial sustainability indicators it is necessary to generalize the ideas of the research:

the main subject of study is the functioning of the company; a key characteristic of the functioning of the company is its financial sustainability, which is interpreted widely as a condition of dialectical equilibrium in which the company is able to retain its quality in terms of dynamic environment and internal transformations and at the same time to ensure the development, the achieving of the goal; a key feature of the potential of the company is the performance quality, which can be a basic development strategy.

The system of financial sustainability indicators presents indicators of organizational, market, operational and financial sustainability. The system of indicators characterizes present condition of the company and prospects for improving the quality of its functioning. It is versatile, customizable for the needs of a specific business.

The system of financial sustainability indicators includes the following modules: quality of products / services; quality of the company management; financial condition of the company (asset quality, resource potential, profit and profitability); operating indicators (economic) risks.

Apparently any of these blocks is the basis of separate methodic of analysis aimed to investigate the condition and dynamics of business activity in one of above mentioned directions. If we collect separate methodics in a complex one, the indicators depicture a comprehensive widespread description of the company's functioning.

The core block of the represented system of financial sustainability indicators is a system of financial condition indicators. The importance of this characteristic of business activity is beyond question. Financial condition is not only a 
concept in classical financial analysis but also an instrument of sustainable development of other spheres of business activity - social and environmental.

Sustainable, that is balanced, development of the company supposes meeting the requirements of different users of analytical work (stakeholders), scanning of management decisions and methods of their implementation. These activities lead to sustainable development of the company as an economic entity, a social institution and an element ecological system.

In represented system of indicators two components - product / service quality and management quality are universal, because they describe the activity of any company despite of size, industry and location.

Other operational risk factors, which take into account specific features of business, are considered in the block of indicators named "Operational risk". Among operating risks we suggest to consider following types of risks: personnel risks, reputation risks, transportation risks, legal risks, natural and environmental risks, political risks. Factors of commercial risks are included in a system of indicators named "Product / service quality", Factors of managerial risks - in a system of indicators named "Management quality".

The main goal of financial sustainability analysis is to search, discover and mobilize the reserves (in other words working balances). In terms of economic analysis reserves are untapped opportunities to increase business activity efficiency. Reserves could be discovered in different areas of business activity. They correspond with blocks of represented system of financial sustainability indicators. According to their nature and source of mobilization we divide reserves in to two groups - implicit and disclosed. Disclosed reserves are evidence of failure and error. They appear in indicators of losses, resource overhead, penalty and defect. Implicit reserves are a matter of heightened interest. They are associated with reduce of efficiency and lack of increase or insufficient increase of business activity productivity. Thus methods of discovering and calculation of implicit reserves are a matter of analytical work.

\section{Conclusion}

A comprehensive indicator of the business activity quality is its financial sustainability.

The stability of the system is a synthesizing term, which consists of a large group of factors and primarily treated as reliability. The loss of stability can occur: a) due to changes in system parameters; b) due to the presence of external influences (in particular, too sizeable or qualitatively incompatible with the system); c) in violation of links in the system when changing the structure of the latter (structural instability).

Stability depends on the ability of a system to maintain its quality in a changing environment and internal transformations (accidental or intentional). According to systems theory, quality is measured in terms of its fitness for purpose of the system. Maintaining stability is the internal goal of the system in contrast to the external, linked to the achievement of competitive advantages and characterizing the relationship with the environment. Therefore, the system should be organized to ensure their own survival, stability in a dynamic environment and development.

Here occurs one of the main contradictions in the system that is enabled through its development. On the one hand, the need to maintain stability gives the system the property of resistance to impacts, external as well as internal. On the other hand, the need of purposeful movement to the goal requires the system to evolve, develop and implement control functions.

Important in this context is the idea of the internal organization of the system. Traditionally, the economic system is seen in orderable sense ("order" - the order). Currently, however, the most appropriate becomes the approach, according to which chaos (disorder) has independent significance to ensure the viability of the system and is one of the systemic factors. Such systems are called evolving: the overall condition of the system stabilizes within the ordered actions, while parts of the system are provided with sufficient autonomy, flexibility and adaptability.

The essential condition for ensuring the sustainability of the economic system is its effective interaction with quality management system (QMS) activities of the organization, which is based on the methodology of total quality management and international quality standards.

Financial sustainability differs from the overall concept of sustainability as a part differs from the whole, while the area of management actions are limited in scope (by means of finance). The main goal of financial sustainability analysis is to search, discover and mobilize the working balances (reserves), untapped opportunities to increase business activity efficiency.

\section{References}

Bakanov, M.I. \& Sholomovich, I.A. (1952). Analysis of Economic Activity of an enterprise. Moscow, Gosfinizdat 
Barilenko, V.I. et al. (2006). Financial Statement Analysis. Moscow, KnoRus.

Batrakova, L.G. (2007). Economic Analysis of bank performance. Moscow, Logos.

Chernenko, A.F. \& Basharina, A.V. (2010). Financial Statement Analysis. Moscow, Feniks.

Doncova, L.V. \& Nikiforova, N.A. (2015). Financial Statement Analysis. Moscow, DiS.

Endovickaya A.V. \& Gilyarovskaya, L.T. (2006). Analysis and estimation of financial stability of commercial firms. Moscow, UNITI-DANA. Gerasimova, E.B. (2010). Turbo-analysis of the bank. Moscow, Forum.

Grachev, A.V. (2010). Financial stability of an enterprise: criteria and methods of estimation in market economy. Moscow, DiS.

Kopchenko, U.E. (2009). Financial provision of bank performance: mechanisms of financing and management. Saratov, SSSEU.

Kovalev, V.V. (2015). Financial management course. Moscow, Prospekt.

Kreinina, M.N. (2004). Financial management. Moscow, DiS.

Larionova, I.V. (2003). Asset-liability Management in commercial bank. Moscow, Consultbankir.

Maidanchik, B.I. (1973). Comparative analysis in machine industry. Moscow, Machinostroenie.

Mamonova, I.D. (1996). Economic Analysis of bank performance. Moscow, Infra-M.

Merriam-Webster Dictionary. Retrieved January 18, 2015, from http://www.merriam-webster.com/dictionary/reliability

Osmolovsky, V.V. at al. (1989). Economic Analysis Theory. Minsk, Vysh.sh.

Ostrinskaya, Z.R. (1971). Analysis of Economic Activity of an enterprise. Moscow, Finansy.

Pereslegin, V.I. et al. (1967). Economic Analysis of the performance of industrial enterprises. Moscow, Mysl.

Petrova, V.I. (2007). Comprehensive analysis of financial activity of the bank. Moscow, Finansy I Statistika.

Sholomovich, I.A. (1938). How to read balance-sheets of an industrial enterprise. Kiev, Gosfinizdat.

Suhova, L.F. et al. (2006). Analysis of financial condition and business-plan of trade company of consumer cooperation. Moscow, Finansy I Statistika.

Veicman, N.R. (1947). Balance-sheets of capitalistic enterprises and their analysis. Moscow, Gosplanizdat.

Veshkin, U.G. \& Avagyan, G.L. (2010). Economic Analysis of bank performance. Moscow, Magistr.

Zharkovskaya, E.P. (2015). Financial Analysis of bank performance. Moscow, Omega-L. 